\title{
Validity and reliability of the Turkish version of the attitudes toward obese persons scale and the beliefs about obese persons scale
}

\author{
Ozden Dedeli ${ }^{1}$, Sibel Aybarc Bursalioglu ${ }^{2}$, Artuner Deveci ${ }^{3}$ \\ 1. Department of Internal Medicine, School of Health, Celal Bayar University, Manisa, Turkey. 2. Department of Business \\ and Administrative Sciences, Faculty of Economics and Administrative Sciences, Celal Bayar University, Manisa, Turkey. 3. \\ Department of Psychiatry Medicine, Faculty of Medicine, Celal Bayar University, Manisa, Turkey.
}

Correspondence: Ozden Dedeli. Adress: Deparment of Internal Medicine, School of Health, Celal Bayar University, Istasyon Mevkii 45020, Manisa, Turkey. Email: ozdendedeli@yahoo.co.uk

Received: April 4, 2014

Accepted: September 16, 2014

Online Published: October 8, 2014

DOI : $10.5430 /$ cns.v2n4p105

URL: http://dx.doi.org/10.5430/cns.v2n4p105

\section{Abstract}

Object: The 20-item Attitudes toward Obese Persons Scale (ATOP) and the 8-item Beliefs about Obese Persons Scale (BAOP) are used in English speaking countries to measure attitudes and beliefs about obese persons. The purpose of this study was to test the validity and reliability of the ATOP and the BAOP in Turkish language.

Methods: It is a methodological study. The study was conducted in Celal Bayar University. The study subjects comprised of 103 School of Health, 105 Faculty of Economics and Administrative Sciences, 94 School of Physical Education, and Sports students. The data were collected by a questionnaire consisting of socio-demographic characteristics, the level of obesity knowledge and the Turkish version of the ATOP (T-ATOP) and the Turkish version of the BAOP (T-BAOP). The psychometric properties of both scales were examined by exploratory and confirmatory factor analysis, internal consistency, intra-rater reliability. Cronbach's alpha coefficients and Spearman Brown split-half were used to assess internal consistency reliability of the scales. Intra-rater reliability of the scales was examined by intraclass correlation coefficients (ICC).

Results: Three factors (i.e., Different Personality, Social Difficulties, and Self-Esteem) of the T-ATOP were established by exploratory factor analysis, and confirmatory factor analysis demonstrated three-factor structure. Internal consistency was supported by Cronbach's alpha (0.86), Spearman Brown split-half value ( 0.75 for the first half) and ( 0.72 for the second half), and intra-rater reliability ( $\mathrm{ICC}=0.78$ ). The results of the exploratory and confirmatory factor analysis demonstrated that the T-BAOP has a structure of the one factor. As for internal consistency of T-BAOP, it was supported by Cronbach's alpha (0.84), Spearman Brown split-half value ( 0.79 for the first half and 0.74 for the second half) and intra-rater reliability $(\mathrm{ICC}=0.80)$.

Conclusions: The T-ATOP and the T-BAOP showed initial evidence of the reliability and validity that can be used in Turkish speaking countries in order to measure attitudes and beliefs about obese persons.

\section{Key words}

Obesity, Attitude, Belief 


\section{Introduction}

Obesity is an important health problem in our country as well as in the world. In addition, the prevalence of overweight and obesity has increased worldwide. According to a research carried out by the Ministry of Health and general directorate of primary health care, in Turkey, the obesity prevalence is much more in women $(41.5 \%)$ than men $(21.2 \%)^{[1]}$.

Obesity is a chronic disorder, which has psychological origin and somatic appearance, caused by the disorder of energy balance. Also obesity has increased the mortality by causing various chronic diseases such as hypertension, hypercholesterolemia, type 2 diabet, atherosclerotic heart disease, respiratory diseases, gout and some types of cancer. Obesity is both a social and economic problem, which influences the individuals negatively by physically, socially, psychologically and decreases the life standart, also adds burden to the treatment and to the health services ${ }^{[2]}$. For obese people, seats have to be replaced in cars, cinemas, sports fields and theatres. So, obesity concerns not only health care professionals; but also engineers, architects and designers. In previous years; while obesity was thought as a sign of wealth, today it is emphasized as a disease. Because of attaching importance to the body image in some societies-being thin or slim-weight has been condemned, obese people have been thought indolent and uncontrolled. Moreover, media has emphasized the importance of being thin for women. In today's world, being thin is often matched with beauty, success, fitness and self-control. Researches indicate strongly that the ideal of being thin is promoted by the print media, particularly magazines aiming at teenage girls and adult women. On the other hand, obesity is considered as an undesirable ideal. The reasons are often more related to cosmetic concerns than to actual or potential medical complications. This negative image has mostly influenced women and caused some psychiatric disorder. It is stated that having a thin image is more important for women of high socio-cultural level than the other women. Because the social media emphazises the physical apperance and ideal body for success and acceptance, obese people have been exposed to stigma, bias and discrimination in academic and business environment. Obese people have been perceived as stupid, lazy, deceitful and been exposed to negative behaviours in many areas of life such as workshops, health units, media and in interpersonal relations ${ }^{[3-5]}$. Even among children, there is a prejudice against obese peers. In the field of education, obese persons have been exposed to negative approaches, abuse and ridicule by both their friends and teachers. Draw attention to the fact that students who are non obese are preffered more to the ones who are overweight (especially women), despite being more qualified $^{[6,7]}$.

"Stigma" and "Bias" are generally negative behaviors that harm relations among people. This situation can emerge in many forms; can be verbal (derision, humiliation, using fake names), physically stigma (shove, push) and some obstacles related to the weight (instruments commonly used in public areas such as chairs, may be small to sit or wardrobes in which, large size of clothes aren't fit). Even more extreme cases, most times "distinguish" has been observed clearly. At some workplaces, there are individuals had needed features; still couldn't work in suitable positions and aren't prefered during the promotion, though. In a study provided that employers have negative thoughts about colleagues, who are overweight, such as; indolent, careless, uncompetitive, undisciplined and sloppy. Also concluded that employees who are overweight work for low wages and rarely promote when compared them to other individuals with the same quality. Experimental researches carried out that when curriculum vitae of the individuals and their photo were presented to the employer, overweight individuals were approached more negatively and their recruitment rate is lower ${ }^{[8-12]}$. Obesity could be affect the individual relationship with health care providers. There were data emphasized health professionals' negative attitudes toward obese patients. A number of investigators have reported that health professionals hold negative views of overweight and obese people. Negative attitudes have been observed in medical students and qualified practitioners, nurses, dietetic students and dietitians and mental health professionals. Doctors, nurses, psychologists, dietitians and trainees' opinions which include that obese persons are unsuccessful, less intelligent, weak-kneed, unhappy and indolent can bring about their prejudice behaviors towards theirs. One of the most important consequence of these negative behaviors is that the obese patients remove from treatment. The researches (especially with women) showed that the cancellation of an appointment is more frequently seen in overweight patients ${ }^{[13-18]}$. 
Health professionals and the society are often believe that obese persons are weak in their fights against the social assumptions. Depression, anger and social withdrawal are more common situations in obese adults who are condemned because of their weight. Some obese adult react to these negative approaches as "acceptance" and "lose self-esteem". This stigma can lead to negative results on eating habits and weight-loss efforts. Some of the obese persons give their reactions against this stigma by much more eating. Due to the difficulties encountered in the field of health, they refrain from taking health care. So, some complications start to develop. Negative attitudes toward obese persons may be relation with belief about the causes of weight gain. In particular, the belief that weight is under volitional control is associated with more negative attitudes and a perception of personal responsibility and blame. Several studies conducted in the youth (15-24 ages), participants, (body image, self esteem and acceptance by society is far more important in this term) shown that being teased because of weight causes social withdrawal, loneliness, depression and suicide ${ }^{[19-22]}$.

Nutrition and healthy life style behaviors such as; increased physical activity and adequate-balanced nutrition are aimed in the treatment of obesity. Although this goal could be seem easy, it is required transforming behaviour into habitual and ensuring the continuity of them. The process of weight loss is a traumatic event for obese person. It has been thought changing negative attitudes and belief about obese persons are important. Recognition of bias in society, developing empathy, determining the needs of obese patients, providing the training and information services about adequatebalanced nutrition, weight control and physical activity to the entire of the society are important. Physical, social and negative attitudes which adversely affect the obese persons must be identified and should be accepted that obesity is a chronic disease which needs to be treated. As a result, it has been thought that social sensitivities will increase ${ }^{[23]}$.

The Attitudes toward Obese Persons Scale (ATOP) and the Beliefs about Obese Persons Scale (BAOP) were developed by Allison et al (1991) in order to measure the attitudes and belifs about obese persons. Both scales are self-administered that are widely used in English speaking countries ${ }^{[24]}$. The purpose of this study was to test the validity and reliability of the Turkish version of the Attitudes Toward Obese Persons Scale (T-ATOP) and the Turkish version of the Beliefs About Obese Persons Scale (T-BAOP).

\section{Methods}

\subsection{Research design}

It is a methodological study.

\subsection{Study setting}

The study was conducted in Celal Bayar University in Manisa, Turkey.

\subsection{Subjects}

The study subjects consisted of three groups: The School of Health students (34.1\%), School of Physical Education and Sports students (31.1\%), and Faculty of Economics and Administrative Sciences students (34.8\%). The students who are 18 years of age and over 18 and can speak Turkish were the eligibility criteria. The study purpose, procedural details, the participant's rights and potential benefits and risks of the study were explained and written consent forms were obtained from them.

\subsection{The instruments}

\subsubsection{A demographic instrument}

A questionnaire was developed by the authors to capture personal information on age, gender, department, marital status and obesity knowledge level ${ }^{[14,24,25]}$. 


\subsubsection{The beliefs about obese persons scale}

The Beliefs About Obese Persons Scale assesses the degree that individual believes obesity is controllable. The BAOP includes 8 -item with a response scale ranging from $-3=$ strongly disagree to $+3=$ strongly agree. Scores range from $0-48$ and 24 is added to the total to remove all negative scores. Higher scores indicate a stronger belief that obesity is not under the obese person's control. Alpha coefficients range from .65 to .82 for a range of samples ${ }^{[25]}$.

\subsubsection{The attitudes toward obese persons scale}

The Attitudes Towards Obese Persons Scale measures positive and negative attitudes about obese persons. The ATOP includes 20 -item with a response scale of $-3=$ strongly disagree to $+3=$ strongly agree. Scores range from $0-120$ and 60 is added to the total to remove negative scores. Higher scores indicate more positive attitudes towards obese persons. Alpha coefficients range from .80 to .84 for a range of samples ${ }^{[25]}$.

\subsection{Procedure}

At the beginning of the study, Allison, one of the developers of both scales, was interviewed via the Internet, and his permission and approval were obtained for the use of the scales in this study. As the first step, the original instruments (English language) were translated by 3 researchers who are fluent in translation. The results of the translations were synthesized by modifying some terms to improve comprehensibility and cultural relevance. Afterwards completion of the synthesis process, the back-translation were performed by another bilingual 2 independent experts. The back-translated versions were conducted by the orginal versions to confirm the adequacy and accuracy of the translation. After examining any discrepancies between the two versions, the content validity was reviewed by an expert committee composed of three nursing Professors and two English language experts. They determined that there was no difference between the meanings of the two versions. Afterwards examining the content validity, a pilot test for comprehensibility and clarity of the scales were carried out on a sample of 5 volunteer university students ( 3 females, 2 males). The respondents were asked if they had any trouble understanding and replying to the items and if they had any suggestions for the questionnaire. The participants reported no specific problems with issues and 8-item the T-BAOP and 20-item the T-ATOP were finalized. The final stage of both scales was used to collect data in this study. Completion of the questionnaire took an average of 30 minutes. The data of the pilot study were not used in the statistical analysis of the research data.

\subsection{Data collection}

Data were collected by the researchers who tested the content of the questionnaire for intra-rater reliability. Data were collected using both scales and a demographic instrument which took a range from 20 to 30 minutes.

\subsection{Data analysis}

Data were analysed using The SPSS for Windows Version 16.0. Afterwards the transmission of data to computer environment and necessary error controls were performed. Descriptive statistics (i.e., mean, standart deviation, percentages) were used to assess the distribution of variables. Validity: The content validity was reviewed by an expert committee composed of three nursing Professors and two English language experts. They determined that there was no difference between the meanings of the two versions. After examining the content validity, a pilot test for comprehensibility and clarity of the scales was conducted on a sample of 5 volunteer university students ( 3 females, 2 males). The Kaiser-Meyer-Olkin (KMO) and Bartlett's Test of Sphericity were examined to evaluate sampling adequacy. KMO was considered as unacceptably low if it is below 0.50 , deemed as poor if between 0.50 and 0.60 , judged as average if between 0.60 and 0.70 , deemed as good if between 0.80 and 0.90 , as excellent if above $0.90^{[26]}$. Because the T-ATOP and the T-BAOP had never been examined in the Turkish population, exploratory factor analysis using a principal components analysis followed by varimax rotation of the extracted factors was performed to examine the underlying factor stuctures of the T-ATOP and the T-BAOP. Factors with an Eigenvalue of 1 or more provided initial factors for further testing. The value of 0.40 or higher on factor loadings was chosen as the significant criteria for assigning items to factors. The conceptual relevance on the basis of empirical evidence was concerned with assignment of items that had significant 
loadings on multiple factors ${ }^{[27]}$. Reliability: The intra-rater reliability was examined by intraclass correlation coefficients (ICC). ICC was classified as high (above 0.60 ), moderate (between 0.60 and 0.30 ) or low (below 0.30 ) in reliability of the scales ${ }^{[28]}$. The internal consistency was examined with Cronbach's alpha coefficients and Spearman-Brown split half coefficients. Cronbach's alpha coefficients and Spearman-Brown split half coefficients were considered as high if above 0.80 , moderate if between 0.60 and 0.80 , and low if below $0.60^{[29,30]} \cdot p$-values less than 0.05 were considered statistically significant.

\subsection{Ethical issues}

This study was approved by the Research Ethics Committee of the Celal Bayar University Faculty of Medicine at Manisa, Turkey. Participants were informed that they could refuse or withdraw from the study at any time. Participants signed a consent form before questionnaires were administered.

Table 1. The study sample characteristics $(\mathrm{n}=302)$

\begin{tabular}{|c|c|c|}
\hline Characteristics & $\mathbf{n}$ & $\%$ \\
\hline \multicolumn{3}{|l|}{ Gender } \\
\hline Female & 118 & 62.3 \\
\hline Male & 114 & 37.7 \\
\hline \multicolumn{3}{|l|}{ Marital status } \\
\hline Married & 7 & 2.3 \\
\hline Single & 295 & 97.7 \\
\hline \multicolumn{3}{|l|}{ School/Faculty } \\
\hline School of Health & 103 & 34.1 \\
\hline School of Physical Education and Sports & 94 & 31.1 \\
\hline Faculty of Economics and Administrative Sciences & 105 & 34.8 \\
\hline \multicolumn{3}{|l|}{ Insurance } \\
\hline Goverment Employee's Retirement Fund (GERF) & 54 & 17.8 \\
\hline The Social Insurance Organization (SSK) & 105 & 34.7 \\
\hline $\begin{array}{l}\text { The Social Insurance Agency of Merchants, Artisans and } \\
\text { Self-Employed (Bağ-kur) }\end{array}$ & 38 & 12.5 \\
\hline Private (out-of-pocket payments) & 5 & 1.6 \\
\hline Green Card (Low income) & 8 & 2.6 \\
\hline Absent & 94 & 31.1 \\
\hline \multicolumn{3}{|l|}{ Economic status } \\
\hline Enough & 110 & 36.4 \\
\hline Partially enough & 157 & 52.0 \\
\hline Inadequate & 35 & 11.6 \\
\hline \multicolumn{3}{|l|}{ Part time/Full time work } \\
\hline Yes & 293 & 79.1 \\
\hline No & 63 & 20.9 \\
\hline
\end{tabular}




\section{Results}

\subsection{Study sample characteristics}

Of the 302 university students 188 were women, while the majority was single (97.7\%). The average age of the students was 21.7 \pm 1.4 (Mean \pm Standart Deviation) years. Most of the students are not from Manisa. They lived with their families, with husband/wife, their friends, alone, and in dormitory. Table 1 presents the demographic and other characteristics for all students. There was no different statistically significant among the students groups regarding to independent variables such as age $(t=258.8, p>.05)$, gender $(t=49.3, p>.05)$, school $(t=42.3, p>.05)$, marital status $(t=227.9, p>.05)$, economic status $(t=46.9, p>.05)$, height $(t=348.8, p>.05)$, weight $(t=97.7, p>.05)$.

The average body mass index (BMI) of the students were $21.8 \pm 3.0 \mathrm{~kg} / \mathrm{m}^{2}$, and $51.7 \%$ of them were not pleased with their weight. $35.8 \%$ of the students who were not pleased with their weight stated that they wanted to lose weight and $15.9 \%$ of them stated that they wanted to gain weight. 39.4\% of them answered "yes" to the question of "During the past six months did you ever attempt to gain or lose weight?". Weight gain or weight loss attempts were detected, respectively; $2.0 \%$ of them taking medical help, $12.5 \%$ of them using drugs head from the social media, $10 \%$ of them did as their family and friends, $18.9 \%$ of them by diet and exercise. $53.8 \%$ of the students stated that there was not obese individual in their family. We asked the students who had obese family members "what they thought about their weight?". $26.2 \%$ of them responded that they tried to lose weight by themselves and $19.5 \%$ of them responded that they weren't interested in weight loss. $58.9 \%$ of the students stated that they had an obese friend. When the students were asked what their friends thought about their weight, their answers were respectevely; $42.4 \%$ of them tried to lose weight, $2.0 \%$ of them received medical help, $2.6 \%$ of them weren't aware of this, $0.7 \%$ of them accepted themselves as healty, $11.2 \%$ of them weren't interested in weight loss. When we asked "how do you define obesity?", $14.9 \%$ of them defined as eating much-weight gain as a result of irregular eating, $63.1 \%$ of them defined as body mass index is over 25 and $22 \%$ of them defined as excessive fat deposition in the body. $93.0 \%$ of the students agreed that the obesity is an ilness, $96.7 \%$ of them agreed that obesity is curable and $98.3 \%$ of them agreed that it must be treated. $94.4 \%$ of them stated they had information about obesity. When sources of information to the students were asked, $32.0 \%$ of them from vocational education and training, $20.2 \%$ of them from television-radio, $16.3 \%$ of them from newspaper-magazine, $9.1 \%$ of them from internet and $31.5 \%$ of them from both vocational education and investigating stated.

\subsection{Validity}

\subsubsection{Content validity}

The content validity was reviewed by an expert committee composed of three nursing Professors and two English language experts. They determined that there was no difference between the meanings of the two versions. After examining the content validity, a pilot test for comprehensibility and clarity of the scales were performed on a sample of 5 volunteer university students ( 3 females, 2 males). The respondents were asked if they had any trouble understanding and replying to the items and if they had any suggestions for the questionnaire. The participants reported no specific problems with issues and 8 -item the T-BAOP and 20-item the T-ATOP were finalized.

\subsubsection{Construct validity}

T-BAOP: Before factor analysis, the KMO measure of sampling adequacy test and Bartlett's Test of Sphericity were conducted. The KMO was 0.88 and the result indicated an adequate sample for the 8 items of the T-BAOP. Result for Bartlett's Test of Sphericity showed statistical significance $\left(\chi^{2}=592.801, p<.000\right)$, which was an adequate sample for factor analysis. The results of the exploratory and confirmatory factor analysis demostrated that the T-BAOP had a structure of one factor. The rotated factor solution is presented Table 2. A factor structure accounted for $42.7 \%$ of the total variance and with an Eingenvalue of 3.42. None of items of the T-BAOP was omitted because the factor loading of the items was above 0.40 . 
Table 2. Exploratory and confirmatory factor analysis of The T-BAOP $(n=302)$

\begin{tabular}{|c|c|c|c|}
\hline Items & Factor Loading & Eingenvalue & $\begin{array}{l}\text { \% Of the } \\
\text { Variance }\end{array}$ \\
\hline $\begin{array}{l}\text { 1-Obesity often occurs when eating is used as a form of compensation for lack of } \\
\text { love or attention. }\end{array}$ & 0.82 & 3.42 & $42.7 \%$ \\
\hline 2-In many cases, obesity is the result of a biological disorder. & 0.98 & & \\
\hline 3-Obesity is usually caused by overeating. & 0.81 & & \\
\hline 4-Most obese people cause their problem by not getting enough exercise. & 0.65 & & \\
\hline 5-Most obese people eat more than nonobese people. & 0.61 & & \\
\hline 6-The majority of obese people have poor eating habits that lead to their obesity. & 0.57 & & \\
\hline 7-Obesity is rarely caused by a lack of willpower. & 0.51 & & \\
\hline $\begin{array}{l}\text { 8-People can be addicted to food, just as others are addicted to drugs, and these } \\
\text { people usually become obese. }\end{array}$ & 0.48 & & \\
\hline
\end{tabular}

T-ATOP: The KMO measure of sampling adequacy test and Bartlett's Test of Sphericity were applied to the data prior to factor extraction to ensure that the characteristics of the data set were suitable for factor analysis. The KMO was 0.82 and the result indicated an adequate sample for the 20 items of the scale. Result for Bartlett's Test of Sphericity showed statistical significance $\left(\chi^{2}=217.413, p<.000\right)$, which was an adequate sample for factor analysis. Exploratory and confirmatory factor analysis were established whether the three-factor structure in the original ATOP had good fit with the data collected in the current study. The result of factor analysis showed that the T-ATOP had a structure of three factors (i.e., Different Personality, Social Difficulties, Self-Esteem). Three factor structure accounted for $42.1 \%$ of the total variance and with an Eingenvalue of 3.60. Eight items were loaded onto Factor 1, explaining 12.5\% of the variance with Eingenvalue of 3.4, which was labeled as Different Personality. Six items were loaded onto Factor 2, explaining 11.3\% of the variance with Eingenvalue of 1.9, which was labeled as Social Difficulties and other six items were loaded onto Factor 3, explaining $11.2 \%$ of the variance with Eingenvalue of 1.6, which was labeled as Self-Esteem. The rotated factor solution is shown in Table 3. Because the factor loading of the items were ranged from 0.40 to 0.83 , none of items of the T-ATOP was omitted.

\subsection{Reliability}

T-BAOP: The adequacy of internal consistency of the T-BAOP was examined with Cronbach's alpha (0.84), Spearman Brown split-half value ( 0.79 for the first half) and ( 0.74 for the second half). The intra-rater reliability was found to be ICC $=0.80$. The mean score of the T-BAOP was showed as 20.1 \pm 5.3 (See Table 4). There was no significant difference among the student groups regarding the mean scores of the T-BAOP $(\mathrm{F}=12.5, p<.01)$.

T-ATOP: Cronbach's alpha (0.86), Spearman Brown split-half value ( 0.75 for the first half and 0.72 for the second half) of the T-ATOP were found as the adequacy of internal consistency. The intra-rater reliability was examined by intraclass correlation coefficients $(\mathrm{ICC}=0.78)$. The internal consistency of each factor was examined with Cronbach's alpha. Cronbach's alpha of three factors were found to be $0.64,0.68$ and 0.62 respectively. The mean score of the T-ATOP was showed as $57.4 \pm 12.9$ (See Table 5). The mean scores of the three factors were obtained to be $3.2 \pm 0.9,3.0 \pm 0.6$ and $3.5 \pm 0.6$ respectively. There was no significant difference among the student groups regarding the mean scores of the T-ATOP $(\mathrm{F}=$ $12.5, p<.01)$.

The significant level of Pearson correlation coefficient was found between the mean scores of the T-ATOP, the mean scores of the T-BAOP and independent variables (gender, age, economic status, BMI, obese friends, obese person in family). Table 6 presents Pearson's correlation coefficient values between the mean scores of the T-ATOP, the mean scores of the T-BAOP and independent variables. A multiple regresyon analysis with the T-ATOP as the criterion variable yielded a multiple correlation coefficient 0.53 for the sample. The T-BAOP predicted $12 \%$ of the variance. The second 
predictor variable was economic status which predicted $8 \%$ of the variance and the third predictor variable was BMI which predicted $6 \%$ of the variance. A multiple regresyon analysis with the T-BAOP as the criterion variable yielded a multiple correlation coefficient 0.42 for the sample. When the T-BAOP scores were applied to multiple regresyon analysis as the criterion variable the T-ATOP was the first predictor again which predicted $16 \%$ of the variance. The second variable was BMI, $3 \%$ of the variance and the third predictor variable was economic status which predicted $3 \%$ of the variance.

Table 3. Exploratory and Confirmatory Factor Analysis of The T-ATOP $(\mathrm{n}=302)$

\begin{tabular}{|c|c|c|c|c|}
\hline Factors & Items & Factor loading & Eingenvalue & $\begin{array}{l}\text { \% Of the } \\
\text { Variance }\end{array}$ \\
\hline \multirow{8}{*}{$\begin{array}{l}\text { Different } \\
\text { personality }\end{array}$} & $\begin{array}{l}\text { 4-Obese workers cannot be as successful as } \\
\text { other workers. }\end{array}$ & 0.53 & 3.4 & 12.5 \\
\hline & 6-Severely obese people are usually untidy & 0.83 & & \\
\hline & $\begin{array}{l}\text { 11-Obese people are often less aggressive than } \\
\text { nonobese people. }\end{array}$ & 0.46 & & \\
\hline & $\begin{array}{l}\text { 12-Most obese people have different } \\
\text { personalities than nonobese people. }\end{array}$ & 0.48 & & \\
\hline & $\begin{array}{l}\text { 14-Most obese people resent normal weight } \\
\text { people. }\end{array}$ & 0.45 & & \\
\hline & $\begin{array}{l}\text { 15-Obese people are more emotional than } \\
\text { nonobese people. }\end{array}$ & 0.49 & & \\
\hline & $\begin{array}{l}\text { 17-Obese people are just as healthy as nonobese } \\
\text { people. }\end{array}$ & 0.63 & & \\
\hline & $\begin{array}{l}20 \text {-One of the worst things that could happen to } \\
\text { a person would be for him to become obese. }\end{array}$ & 0.52 & & \\
\hline \multirow{6}{*}{ Social difficulties } & $\begin{array}{l}\text { 5-Most nonobese people would not want to } \\
\text { marry anyone who is obese. }\end{array}$ & 0.83 & 1.9 & 11.3 \\
\hline & 7-Obese people are usually sociable. & 0.57 & & \\
\hline & $\begin{array}{l}\text { 10-Most people feel uncomfortable when they } \\
\text { associate with obese people. }\end{array}$ & 0.40 & & \\
\hline & $\begin{array}{l}\text { 16-Obese people should not expect to lead } \\
\text { normal lives. }\end{array}$ & 0.50 & & \\
\hline & $\begin{array}{l}18 \text {-Obese people are just as sexually attractive } \\
\text { as nonobese people. }\end{array}$ & 0.63 & & \\
\hline & 19-Obese people tend to have family problems. & 0.54 & & \\
\hline \multirow{6}{*}{ Self-esteem } & $\begin{array}{l}\text { 1-Obese people are as happy as nonobese } \\
\text { people. }\end{array}$ & 0.41 & 1.6 & 11.2 \\
\hline & $\begin{array}{l}\text { 2-Most obese people feel that they are not as } \\
\text { good as other people. }\end{array}$ & 0.43 & & \\
\hline & $\begin{array}{l}\text { 3-Most obese people are more self-conscious } \\
\text { than other people. }\end{array}$ & 0.45 & & \\
\hline & $\begin{array}{l}\text { 8-Most obese people are not dissatisfied with } \\
\text { themselves. }\end{array}$ & 0.44 & & \\
\hline & $\begin{array}{l}\text { 9-Obese people are just as self-confident as } \\
\text { other people. }\end{array}$ & 0.60 & & \\
\hline & $\begin{array}{l}\text { 13-Very few obese people are ashamed of their } \\
\text { weight. }\end{array}$ & 0.49 & & \\
\hline
\end{tabular}


Table 4. The mean scores, standart deviations, intraclass correlation coefficients of the T-BAOP $(n=302)$

\begin{tabular}{lcccccc}
\hline Groups & $\boldsymbol{n}$ & Mean \pm SD & Range & $\boldsymbol{r}$ & $\boldsymbol{p}$ & $\begin{array}{l}\text { Cranbach's } \\
\text { alpha }\end{array}$ \\
\hline $\begin{array}{l}\text { School of Health } \\
\begin{array}{l}\text { Faculty of Economics and } \\
\text { Administrative Sciences }\end{array}\end{array}$ & 103 & $20.9 \pm 5.3$ & $9-34$ & 0.80 & 0.00 & 0.79 \\
$\begin{array}{l}\text { School of Physical } \\
\text { Education and Sports }\end{array}$ & 105 & $20.2 \pm 5.0$ & $7-32$ & & & \\
\hline
\end{tabular}

Note. $\mathrm{SD}=$ Standart Deviation

Table 5. The mean scores, standart deviations, intraclass correlation coefficients of the T-ATOP $(\mathrm{n}=302)$

\begin{tabular}{lllllll}
\hline Groups & $\boldsymbol{n}$ & Mean \pm SD & Range & $\boldsymbol{r}$ & $\boldsymbol{p}$ & Cranbach's alpha \\
\hline $\begin{array}{l}\text { School of Health } \\
\begin{array}{l}\text { Faculty of Economics } \\
\text { Administrative Sciences }\end{array}\end{array}$ & 103 & $63.0 \pm 1.3$ & $24-98$ & 0.78 & 0.00 & 0.82 \\
$\begin{array}{l}\text { School of Physical } \\
\text { Education and Sports }\end{array}$ & 94 & $56.2 \pm 1.1$ & $26-83$ & & & \\
\hline
\end{tabular}

Note. $\mathrm{SD}=$ Standart Deviation

Table 6. Statistical correlations of between the T-ATOP, the T-BAOP, and variables $(\mathrm{n}=302)$

\begin{tabular}{|c|c|c|c|}
\hline \multirow[b]{2}{*}{ Variables } & \multicolumn{3}{|c|}{ Groups } \\
\hline & School of Health & $\begin{array}{l}\text { Faculty of Economics and } \\
\text { Administrative Sciences }\end{array}$ & $\begin{array}{l}\text { School of Physical } \\
\text { Education and Sports }\end{array}$ \\
\hline \multicolumn{4}{|l|}{ ATOP } \\
\hline Age & $r=0.09$ & $r=0.04$ & $r=-0.00$ \\
\hline Gender & $r=0.18$ & $r=0.11$ & $r=-0.00$ \\
\hline Economic status & $r=0.15$ & $r=0.78^{\#}$ & $r=0.03$ \\
\hline BMI & $r=0.56^{\#}$ & $r=-0.00$ & $r=0.01$ \\
\hline Obese friends & $r=0.09$ & $r=-0.25^{*}$ & $r=-0.61$ \\
\hline Obese person in familiy & $r=0.01$ & $r=0.02$ & $r=-0.30$ \\
\hline BAOP & $r=0.68^{\#}$ & $r=0.54^{\#}$ & $r=0.55^{\#}$ \\
\hline \multicolumn{4}{|l|}{ BAOP } \\
\hline Age & $r=0.08$ & $r=0.09$ & $r=-0.02$ \\
\hline Sex & $r=0.13$ & $r=0.06$ & $r=-0.07$ \\
\hline Economic status & $r=0.06$ & $r=0.92^{\#}$ & $r=0.03$ \\
\hline BMI & $r=0.62^{\#}$ & $r=-0.10$ & $r=0.04$ \\
\hline Obese friends & $r=-0.12$ & $r=0.68^{\#}$ & $r=0.01$ \\
\hline Obese person in familiy & $r=0.03$ & $r=-0.03$ & \\
\hline ATOP & $r=0.68^{\#}$ & $r=0.54^{\#}$ & \\
\hline
\end{tabular}

Note. ${ }^{\#} p<0.01,{ }^{*} p<0.05$ 


\section{Discussion}

Negative societal attitudes are often directed towards obese youth and adults who are frequently targets of weight-based stigma, prejudice, and discrimination. Obese persons face bias in employment settings, health care facilities, educational instutions, interpersonal relationships and in the media, where portrayals of obese persons are particularly as merciless ${ }^{[31]}$. Allison et al (1991) developed the scales which were labeled the Attitudes Toward Obese Persons Scale and the Beliefs About Obese Persons Scale to measure beliefs and attitudes towards obese persons in English language ${ }^{[25]}$. In the current study, we aimed translate both scales into Turkish language and to establish the reliability and validity of the Turkish language version of the ATOP and the BAOP. This study verified the validity and satisfactory reliability of the T-ATOP and T-BAOP to assess attitudes and beliefs about obese persons. As the first step, the original English instruments were translated by 3 researchers who are fluent in translation. The results of the translations were synthesized by modifying some terms to improve comprehensibility and cultural relevance. After completion of the synthesis process, the back-translation was performed by another bilingual 2 independent experts. In addition, the accuracy and clarity of the items on the T-ATOP and T-BAOP were examined carefully by an expert committee composed of three nursing Professors and two English language experts and pilot testing for cultural relevance. The T-ATOP and the T-BAOP indicated good content validity. There is a well-documented sequential process of scale's adaptation to be used in different cultures and it is well known that translation must be validated to achieve an equivalent scale and to allow comparability of data ${ }^{[32]}$.

The psychometric properties of the T-ATOP and the T-BAOP were performed with a group consisting of students in three department: 103 School of Health, 94 School of Physical Education and Sports and 105 Faculty of Economics and Administrative Sciences in Celal Bayar University. In our study, there was no statistically significant difference among the student groups regarding independent variables (age, gender, school, marital status, economic status, height and weight). There was no significant difference among the student groups regarding the mean scores of the T-BAOP and the mean scores of the T-ATOP. The mean scores of the T-ATOP were consistently and strongly correlated with the mean scores of the T-BAOP. Allison et al (1991) performed these scales with 514 members of the National Association to Advance Fat Acceptance (NAAFA), 52 graduated students and 72 undergraduated students. They reported that there was a significant correlation between the total ATOP scores and the total BAOP scores ${ }^{[25]}$. The findings of our study and the results of his research were compared as to the mean scores of both scales as well as their relationship that was similar.

For factor analysis, approximately 5-10 samples per item are considered adequate ${ }^{[33]}$. Considering 10 samples per item of the T-ATOP with 20 items (i.e., 200 samples) and 10 samples per item of the T-BAOP with 8 items (i.e. 80 samples) minumum sample size should be 280. A sample size of 302 in our study was satisfactory for the factor analysis. The KMO was 0.82 and the result indicated an adequate sample for the 20 items of the T-ATOP. Result for the Bartlett's Test of Sphericity showed statistical significance $\left(\chi^{2}=217.413, p<.000\right)$ which was also an adequate sample for factor analysis. As for the T-BAOP, the KMO $(0.88)$ and the Bartlett's Test of Sphericity $\left(\chi^{2}=592.801, p<.000\right)$, results of the T-BAOP indicated that our data provided the psychometric criteria for factor analysis. The factor structure of T-ATOP was found to be similar to the original ATOP. Three factors defined as Different Personality (Factor 1), Social Difficulties (Factor 2) and Self-Esteem (Factor 3) were established by exploratory factor analysis and the three-factor structure were demonstrated by confirmatory factor analysis. The results of exploratory and confirmatory factor analysis provided that the T-BAOP had a structure of the simple factor like the original BAOP. The 8 items the T-BAOP explained $42.7 \%$ of the total variance and the 20 items the T-ATOP explained $42.1 \%$ of the total variance. It was revealed that factor loading of items of the T-BAOP ranged from 0.51 to 0.98 and factor loading of items of the T-ATOP ranged from 0.41 to 0.83 . None of items of the T-BAOP and the T-ATOP were omitted because the factor loading of the items were above 0.40. Each factor provided eingenvalue $>1$. These findings indicated good construct validity. Construct validity of the T-ATOP and the T-BAOP were supported by factor analysis. The results of the factor analysis showed that in the original ATOP and BAOP had good fit with the data collected in the current study ${ }^{[25]}$. 
Reliability was demonstrated by intra-rater reliability and internal consistency reliability. T-ATOP and T-BAOP demonstrated good internal consistency when measured by Cronbach's alpha and Spearman Brown split-half value. Cronbach alpha (0.86) and Spearman Brown split-half value ( 0.75 for the first half and 0.72 for the second half) of the T-ATOP were a moderate level of satisfaction compared to the original ATOP ${ }^{[25]}$. Cronbach alpha and Spearman Brown split-half value of the T-BAOP were found to be 0.84 and 0.79 for the first half and 0.74 for the second half. Allison et al. (1991) found that Cronbach alpha ranged from 0.65 to 0.82 . The findings of internal consistency reliability of the T-BAOP were compared with the results of Allison et al (1991) which were a moderate level of satisfaction ${ }^{[25]}$. Intra-rater reliability was calculated to measure ICC of the T-ATOP as well as the T-BAOP. The ICC ranged from 0.70 to 0.89 for both scales. These results supported good intra-rater reliability and satisfactory internal consistency of both scales.

While the T-BAOP accounted for $16 \%$ of the variance in the mean scores of the T-ATOP, the T-ATOP accounted for $12 \%$ of the variance in the mean scores of the T-BAOP. The mean scores of the T-BAOP were also influenced by BMI and economic status which accounted for each of them $3 \%$ of the variance. Also, the mean scores of the T-ATOP were influenced by BMI and economic status. Economic status which predicted $8 \%$ of the variance of the T-ATOP. Also, BMI which predicted $6 \%$ of the variance of the T-ATOP. Especially, School of_Health students' mean scores of the T-BAOP as well as the T-ATOP were higher than other students. There was statistically significant correlation between BMI, T-BAOP scores, and T-ATOP scores ( $r=0.56$ for the T-ATOP; $r=0.62$ for the T-BAOP). This could indicate that School of Health students had a positive attitudes and belief about obese persons, because they have empathy and holistic approaches. In contrast, School of Physical Education and Sports students had negative attitudes and belief about obese persons. Because their mean scores of the T-BAOP and the T-ATOP were lower than other students. This could indicate that these students who believe that obesity is not largely under the obese person's control tend to have more positive attitudes toward obese persons than those who believe obesity can be controlled by the obese person. When Faculty of Economics and Administrative Science students' mean scores of both scale were compared with other student, they had neutral attitudes and belief about obese persons. In addition, there was statistically significant correlation between economic status and both scale scores ( $r=0.78$ for the T-ATOP; $r=0.92$ for the T-BAOP). In recent years, obesity has been considered as an indicator of richness. Nowadays, obesity is described as a disease. Comfort and conveniences of modern living could be the cause of obesity. Faculty of Economics and Administrative Science students might believe that people with high income could have a better life standart and therefore they might believe that obesity could be influenced by high economic status, and those who are affluent could tend to be obese.

\section{Conclusion}

This research was the first study to translate, and to test psychometric properties of the ATOP and the BAOP for Turkish population. This study provides evidence to support the content and constuct validity as well as the internal consistency and intra-rater reliability of the T-ATOP and the T-BAOP. The findings of this study support the validity and reliability of the T-ATOP and T-BAOP as the instruments to assess of attitudes and beliefs about obese persons in Turkish population. Therefore, further studies that confirm our results is recommended. Our findings suggested that the T-ATOP and the T-BAOP should be tested in other population who have age, BMI, economic status, education difference in the way of attitudes and beliefs about obese persons.

\section{Acknowledgements}

We would like to thank Administrator of School of Health, Dean of Faculty of Economics and Administrative of Science School of Physical Education and Sports and the persons who participated in.

\section{Conflict of interest}

The authors declare no conflict of interest. 


\section{References}

[1] Obesity prevention and control programme 2014. [Internet]. [cited 2013 July 20]. Available from:

http://www.istanbulsaglik.gov.tr/w/sb/egt/pdf/obezite.pdf.

[2] Malnick SDH, Knobler H. The medical complications of obesity. Qxford Journal Medicine. 2006; 99: 565-579. doi:10.1093/qjmed/hc1085. http://dx.doi.org/10.1093/qjmed/hcl085

[3] Lissner L. Psychosocial aspects of obesity: Individual and societal perspectives. Scandinavian Journal of Nutrition Naringsforskning. 1997; 41: 75-9.

[4] Aslan HS. Relationship between body image, eating disorders and the media. The Journal of Psychiatry and Neurological Sciences. 2001; 14(1): 41-7.

[5] Balcioglu I, Baser ZS. The psychiatric aspects of obesity. Istanbul University Medical Faculty Continue Medical Education Program. 2008. http://www.ctf.edu.tr/stek/pdfs/62/6232.pdf.

[6] Sztainer DE, Story M, Arris T. Beliefs and attitudes about obesity among teachers and school health care providers working with adolescents. Journal of Nutrition Education. 1999; 31(1): 3-9. http://dx.doi.org/10.1016/S0022-3182(99)70378-X

[7] Gipson GW, Reese S, Vieweg WVR, et al. Body image and attitude toward obesity in an Historically Black University. Journal of The National Medical Association. 2005; 97(2): 225-36. PMid:15712786

[8] Puhl RM, Brownell KD. Psychosocial origins of obesity stigma:Toward changing a powerful anf pervasive bias. Obesity Reviews. 2003; 4(4): 213-27. http://dx.doi.org/10.1046/j.1467-789X.2003.00122.x

[9] Puhl RM, Heuer CA. The stigma of obesity: A review and update. Obesity. 2009; 17(5): 941-64. PMid:19165161 http://dx.doi.org/10.1038/oby.2008.636

[10] Latner JD, O’Brien KS, Durson LE, Brinkman LA, MacDonald T. Weighing obesity stigma: the relative strength of different forms of bias. International Journal of Obesity. 2008; 32(7): 1145-52. PMid:18414421 http://dx.doi.org/10.1038/ijo.2008.53

[11] Hilbert A, Rief W, Braehler E. Stigmatizing attitudes toward obesity in a representative population-based sample. Obesity. 2008; 16(7): 1529-1534. PMid:18464749 http://dx.doi.org/10.1038/oby.2008.263

[12] Crandall CS, Schiffhauer KL. Anti-fat prejudice: beliefs, values, and American culture. Obesity Research. 1998; 6(6): 458-60. http://dx.doi.org/10.1002/j.1550-8528.1998.tb00378.x

[13] Schwartz BM, Chambliss HN, Brownell KD, Blair SN, Billington C. Weight bias among health professionals specializing in obesity. Obesity Research. 2003; 11(9): 1033-39. PMid:12972672 http://dx.doi.org/10.1038/oby.2003.142

[14] Magliocca KR, Jabero MF, Alto DL, Magliocca JF. Knowledge, beliefs, and attitudes of dental and dental hygiene students toward obesity. Journal of Dental Education. 2005; 69(12): 1332-39.

[15] Berryman DE, Dubale GM, Manchester DS, Mittelstaedt R. Dietetics students possess negative attitudes toward obesity similar to nondietetics students. Journal of American Dietetic Association. 2006; 106(10): 1678-82. PMid:17000203 http://dx.doi.org/10.1016/j.jada.2006.07.016

[16] Bocquier A, Verger P, Basdevant A., et al. Overweight and obesity: Knowledge, attitudes, and practices of General Practitioners in France. Obesity Research. 2005; 13(4): 787-795. PMid:15897489 http://dx.doi.org/10.1038/oby.2005.89

[17] Brown I, Stride C, Psarou A, Brewins L, Thompson J. Management of obesity in primary care: nurses' practices, beliefs and attitudes. Journal of Advanced Nursing. 2007; 59(4): 329-41. PMid:17635298 http://dx.doi.org/10.1111/j.1365-2648.2007.04297.x

[18] Chambliss HO, Finley CE, Blair SN. Attitudes toward obese individuals among exercise science students. Official Journal of the American College of Sports Medicine. 2003; 36(3): 468-74.

[19] Schafer MH \& Ferraro KF. The stigma of obesity: Does perceived weight discrimination affect identity and physical health? Social Psychology Quarterly. 2001; 74(1): 76-97. http://dx.doi.org/10.1177/0190272511398197

[20] Harvey EL \& Hill AJ. Health professionals' views of overweight people and smokers. International Journal of Obesity. 2001; 25(8): 1253-61. PMid:11477512 http://dx.doi.org/10.1038/sj.ijo.0801647

[21] Bal O, Ozgur G, Gumus-Babacan A. Methods of coping with stress in obese individuals. Journal of Cumhuriyet University School of Nursing. 2006; 10(3): 20-8.

[22] Pinar R. Obese patients with depression, self-esteem and body image: A Comparative Study. Journal of Cumhuriyet University Nursing High School. 2000; 6(1): 30-41.

[23] Faith MS, Fontaine KR, Cheskin JL, Allison DB. Behavioral approaches to the problems of obesity. Behavior Modification. 2000; 24(4): 459-93. PMid:10992608 http://dx.doi.org/10.1177/0145445500244001

[24] Allison DB, Basile VC, Yuker HE. The measurement of attitudes toward and beliefs about obese person. International Journal of Eating Disorder. 1991; 10(5): 599-607. 
[25] Dedeli O, Fadiloglu C. Development and evaluation of the Health Balief Model Scale in obesity. TAF Preventive Medicine Bulletin. 2011; 10(5):533-42. http://dx.doi.org/10.5455/pmb.20110118022318

[26] Kaiser HF. An index of factorial simplicity. Psychometrika.1974; 39(1): 31-6. http://dx.doi.org/10.1007/BF02291575

[27] Campbell DT, Fiske JL. Convergent and discriminant validation by the multitrait-multimethod matrix. Psychological Bulletin. 1959; 56(2): 85-105. http://dx.doi.org/10.1037/h0046016

[28] Bland J, Altman DG. Measuring agreement in method comparison studies. Statistical Methods in Medical Research. 1999; 8(2): 135-60. http://dx.doi.org/10.1191/096228099673819272

[29] Andresen EM. Criteria for assessing the tools of disability outcomes research. Archives Physical Medicine and Rehabilitation, 2000; 81(Suppl 2): 15-20. http://dx.doi.org/10.1053/apmr.2000.20619

[30] Cronbach LJ.Coefficient alpha and internal structure of test. Psychometrika.1951; 16 (3): 297-334. http://dx.doi.org/10.1007/BF02310555

[31] Puhl RM, Masheb RM, White MA, Grilo CM. Attitudes toward obesity in obese persons: A matched comprasion of obese women with and without binge eating. Eating Weight Disorders. 2010; 15(3): 173-9.

[32] Guillemin EG, Bombardier C, Beaton D. Cross cultural adaptation of health related quality of life measures: literature review and proposed guidelines. Journal of Clinical Epidemiolog. 1993; 46(12): 1417-32. http://dx.doi.org/10.1016/0895-4356(93)90142-N

[33] Devillis RF. Scale development: Theory and applications (2nd ed). Thousand Oaks, CA:Sage Publications.2003. 